\title{
SOBRE EL INDIGENISMO EN EL MÉXICO POSREVOLUCIONARIO: APORTACIONES DE GREGORIO LÓPEZ Y FUENTES*
}

\author{
Teodosio Fernández
}

Universidad Autónoma de Madrid

Los acontecimientos que se desarrollaron en México entre las fechas aproximadas de 1910 y 1917 son bien conocidos: en su conjunto constituyeron lo que se denomina la «Revolución Mexicana», y desde entonces la historia de aquel país es su consecuencia directa, en cualquiera de los aspectos que se someta a examen. El desarrollo de la literatura ofrece un buen ejemplo, en especial por lo que hace a la narrativa: con el lejano precedente de Los de abajo, que Mariano Azuela publicó por primera vez en la prensa de El Paso, en 1915, la «novela de la Revolución» es parte fundamental de la producción literaria nacional durante los años treinta y cuarenta, y ese tema encuentra aún eco en los novelistas contemporáneos. Alguna aportación notable se debe a Gregorio López y Fuentes, un escritor no demasiado conocido que formó en las filas de Venustiano Carranza, aunque eso - Carranza era tal vez la opción patrocinada por «una burguesía nacional que ha arrastrado tras de sí a la pequeña burguesía y al movimiento obrero confundido por la influencia anarquista y anarcosindicalista» ${ }^{1}$ - no fue obstáculo para que sintiese por Emiliano Zapata la admiración que se revela en Tierra. La revolución agraria en México (1932), una de las novelas que dedicó a evocar los

* En junio de 1986, en la Universidad Autónoma de Madrid, María del Mar Paúl Arranz presentó una excelente Memoria de Licenciatura titulada «Gregorio López y Fuentes: Indigenismo y Revolución». Yo dirigí (exagero, sin duda, mi contribución) ese trabajo, y de aquella investigación proceden en buena medida las reflexiones que siguen. En septiembre de 1988 las expuse en Sevilla, con ocasión de un seminario sobre narrativa indigenista que organizó la Universidad Internacional Menéndez y Pelayo. Una vez más agradezco a María del Mar Paúl Arranz la valiosa ayuda que me prestó a distancia.

1 Véase Rogelio Rodríguez Coronel, prólogo a La novela de la Revolución Mexicana, La Habana, Casa de las Américas, Serie «Valoración Múltiple», 1975, p. 20. 
episodios revolucionarios. De ellos se ocupó también en Campamento (1931) y en ;Mi general! (1934), y una y otras dieron a López y Fuentes un lugar entre los narradores que - como Martín Luis Guzmán, Rafael Felipe Muñoz, Francisco L. Urquizo, José Rubén Romero, José Mancisidor, y otros- siguieron los pasos de Azuela y recuperaron anécdotas, episodios, recuerdos de los caudillos y de los hechos de armas, y hablaron de rebeliones que buscaron la justicia y derivaron en la corrupción o la traición de los ideales revolucionarios. Sin embargo, el interés fundamental de López y Fuentes tal vez radica sobre todo en El indio (1935) y en Los peregrinos inmóviles (1944), otras novelas que también le pertenecen: ellas lo convierten en un destacado representante de la narrativa indigenista mexicana, que en alguna medida inauguró. Esa condición justifica las reflexiones que siguen.

Desde luego, la aparición — tardía - del indigenismo en México está estrechamente relacionado con la atmósfera intelectual posrevolucionaria. Hay que tener en cuenta que la Revolución (con el pensamiento que generó, o el aparato retórico que se fue construyendo en torno a ella) fomentó la conciencia de la identidad mexicana o al menos la pretensión de definirla, y que esa pretensión derivó en actitudes nacionalistas que obligadamente llevaban a valorar el pasado indígena sobre la herencia europea. Era la culminación de un proceso tempranamente iniciado como reacción frente al positivismo dominante en la época de Porfirio Díaz $^{2}$, sobre todo desde que los miembros del Ateneo de la Juventud, fundado en 1908 (entre ellos se contaban Antonio Caso, Alfonso Reyes, José Vasconcelos y Pedro Henríquez Ureña) pretendieron salvar al hombre «ontológicamente», e hicieron suyas las intenciones de Justo Sierra — curiosamente, uno de los grandes intelectuales del porfiriato- de «nacionalizar la ciencia» y «mexicanizar el saber». A la hora de las propuestas renovadoras se inclinaron por soluciones espiritualistas, pero ningún propósito regenerador podía mostrar solidez sin ofrecer salidas para los indígenas, que, como la Revolución hizo evidente, constituían un aspecto fundamental del problema mexicano: ahí estaban sobre todo los campesinos que dirigía Emiliano Zapata en el sur, donde eran muchas las comunidades despojadas de sus tierras. Los políticos se vieron obligados a prestarles atención, empezando por Francisco I. Madero, que al menos en el artículo B de su Plan político-social hizo referencia al tema: «se protegerá en todo sentido a la raza indígena - aseguraba-, procurando por todos los medios su dignificación y prosperidad». Aunque durante mucho tiempo las promesas de la Revolución habían de quedar en promesas, al menos entonces hubo ocasión para la esperanza, y para el nacimiento de un mito relacionado con los orígenes y con el regreso a la propiedad comunal de la tierra, el de Emiliano Zapata, y luego para que Vasconcelos

2 En ese largo período no dejó de manifestarse, desde luego, la pretensión de mejorar las condiciones de vida del indígena por medio de la educación, con la esperanza de que ésta le ayudase a mejorar sus condiciones de vida. En la práctica eso equivalía a su asimilación, con resultados inevitables y penosos: envueltos en una lucha desigual, los indios se revelaron «inferiores» en la lucha por los terrenos de labranza, de los que fueron en buena parte despojados. Las teorías evolucionistas de Darwin y los presupuestos de Spencer prestaban entonces justificación «científica» al triunfo de los más aptos y al sojuzgamiento del campesinado. 
forjase en los años veinte una mitología del mestizaje, la de la «raza cósmica». Y la esperanza había de renacer con fuerza bajo la presidencia de Lázaro Cárdenas (1934-1940) ${ }^{3}$, durante la cual no fueron pocas las tierras repartidas - casi diez millones de hectáreas entre ochocientos mil campesinos-, creándose un clima de verdadera reforma agraria. Por otra parte, Cárdenas dio al nacionalismo un impulso nuevo - fomentado por el enfrentamiento con los Estados Unidos, que tuvo su episodio fundamental en la nacionalización del petróleo-, y el interés por la redención del indio se plasmó en la creación del Instituto Nacional Indigenista y en el relanzamiento de la educación. Por esas y otras razones, la etapa cardenista fue tal vez la última que permitió abrigar ilusiones, que fueron difuminándose a partir de 1940. Entonces vendrían las preguntas, y al tiempo la decepción y el sentimiento del fracaso. En 1943 ya Jesús Silva Herzog pudo escribir sobre «La Revolución Mexicana en crisis» ${ }^{4}$, y referirse a la corrupción moral extendida en todas las esferas de la vida pública. En 1947 Daniel Cosío Villegas insistiría en el diagnóstico de «La crisis de México»" constatando el agotamiento de todas las metas revolucionarias. La Revolución empezaba a ser cosa del pasado, y Silva Herzog lo declaró así en $1950^{6}$.

Desde luego, los escritores se habían anticipado (desde Azuela) en la manifestación de ese escepticismo, al menos en lo referente a la condición humana. Eso era también una consecuencia de la Revolución y del nacimiento de esa conciencia de «ser mexicano», que llevaba aparejados el reconocimiento del entorno y la defensa del individuo, por primera vez dotado de dignidad incluso en la opresión y en la miseria, y a pesar de todos los complejos de inferioridad. Inseparable de ese ambiente general, Gregorio López y Fuentes es a la vez el narrador que mejor representa las inquietudes de la etapa de Cárdenas y de la novela nacional revolucionaria: el había exaltado a Zapata y había descubierto las condiciones infrahumanas del campesinado, en Tierra, y había de poner de manifiesto los abu-

3 Conviene no olvidar que con Cárdenas se expropiaron las compañías petroleras norteamericanas, en 1938. Sin duda también facilitó la lucha obrera contra las empresas, y el desarrollo de las cooperativas entre los campesinos. Fue el relanzamiento de un espíritu revolucionario que tal vez no había existido - o había sido marginal, con manifestaciones políticas como la fundación del Partido Comunista Mexicano en 1919, o literarias, como el poemario Sangre roja (1923), de Carlos Gutiérrez Cruz, o como Urbe, superpoema bolchevique que el estridentista Manuel Maplés Arce dio a conocer en 1924- y que de algún modo se plasmó en la creación del Partido Nacional Revolucionario. Con ese planteamiento parece coincidir el surgimiento de la novela de la Revolución, a fines de los años veinte, que pone fin a una novela «colonialista» que se había desarrollado entre 1917 y 1929 en busca de una identidad que era la de los ateneístas, la de una burguesía que aspiró por entonces a la creación de un capitalismo nacional. Desde luego, hubo planteamientos bastante más radicales que los de la Ideología Nacional Revolucionaria, y una novela "proletaria» como La ciudad roja (1931), de José Mancisidor, constituye prueba excelente. Mancisidor fue de los intelectuales que en Jalapa se acercaron a la clase obrera y al marxismo. Él impulsó después en México, en 1935, la creación de una Liga de Escritores y Artistas Revolucionarios (LEAR), en la que formaron también Rafael Felipe Muñoz y José Rubén Romero. José Bustillo Oro y Mauricio Magdaleno propugnaron por esas fechas un teatro revolucionario.

4 Publicado en Cuadernos Americanos, 1943, págs. 32-55.

5 Publicado en Cuadernos Americanos, 1947, págs. 29-51.

6 En «La revolución mexicana es ya un hecho histórico», extracto en ¿Ha muerto la Revolución Mexicana?, México, Premia Editora, 1978, págs. 113-120. 
sos de las compañías petrolíferas en Huasteca. Novela del petróleo (1939); y él fue el primero en llevar a la novela la nueva actitud hacia el indio, cuya importancia en el país parece descubrirse por primera vez. En este aspecto la época ofrece especial interés, pues el nacionalismo mexicano halló en el indígena todo un pasado precolombino incontaminado. Los intelectuales se lanzaron de pronto a su reivindicación, a la vez que los políticos parecían dispuestos a redimirlo: los años treinta vieron el descubrimiento por Alfonso Caso de las ruinas de Monte Albán y la demostración de la grandeza prehispánica, y la promulgación de leyes en favor del indio (se lo equiparó en derechos a blancos y mestizos); se pusieron en marcha distintas campañas de alfabetización, y se crearon instituciones que procurasen su incorporación a la sociedad mexicana. De ese entusiasmo participaron antropólogos, sociólogos, etnólogos y artistas, y la conjunción de factores diversos dio al indigenismo mexicano unos caracteres peculiares: desde luego, ese indigenismo era reivindicativo - alejado en consecuencia del idealizador indianismo decimonónico-, en la medida en que no podían no denunciarse las injusticias que padecía, pero a la vez — sin hacer del indígena un elemento exótico o decorativo- lo que interesaba de él —más que su miseria presente, su opresión, su degradación - era lo que representaba de un pasado perdido; el indio era lo auténticamente nacional, depositario de una esencia que había sobrevivido a la colonización y que podía servir para definir la identidad propia frente al exterior.

Esos ingredientes de idealización y de denuncia fueron combinados por cada cual en distinta medida, y eso sobre todo cuando, en la etapa del «marxista» Cárdenas, los ideales revolucionarios parecían guardar relación con la reforma agraria y con otras tareas aún no realizadas. Con desencanto o con actitudes críticas se analizaban los escasos resultados obtenidos hasta el momento, y esa es la labor que, con el indio como pretexto, empezaron a abordar los narradores. López y Fuentes aludió a la situación de los «naturales» (sus problemas eran en buena medida los de todo el campesinado mexicano) en novelas como Campamento o Tie$r r a$, y lo convirtió en el tema central de El indio. Por primera vez el indígena y sus problemas se convertían en protagonistas de un relato, iniciando un subgénero que tuvo pronto continuadores: a él pertenecen Aztlán, tierra de garzas (1935), de Rubén Campos, y El resplandor (1937), de Mauricio Magdaleno, y San Gabriel de Valdivias, comunidad indígena (1938), de Mariano Azuela 7. No es difícil encontrar en ellas características comunes: con el enfoque realista que distinguía a la novela de la Revolución, analizaban el problema del indio como una confirmación de que la Revolución había fracasado, incapaz de rescatar de la miseria, de la desconfianza y de la apatía a quienes según la retórica al uso eran depositarios de la esencia nacional. El apogeo de la protesta indigenista hacia coin-

7 El indigenismo mexicano no cuenta con demasiados precedentes. Tal vez el más significativo es Tomóchic (1892), novela en la que Heriberto Frías aprovechó sucesos reales para criticar los atropellos de Porfirio Díaz. Antes la literatura mexicana no había dejado de idealizar el pasado indígena para condenar la presencia española en América, y a Eligio Ancona se deben los mejores resultados de ese resentimiento: La Cruz y la espada (1866) o Los mártires del Anáhuac (1870). Poco más merece resaltarse. 
cidir, en consecuencia, las pretensiones de rescatar esa esencia nacional con la crítica del proceso sociopolítico posterior a los hechos bélicos, y tal vez con la manifestación más o menos encubierta de una actitud negativa hacia el mismo hecho revolucionario. No está de más advertir que esta crítica parece el objetivo primordial, y no están descaminados los continuos reproches que se han hecho a estos narradores por sus acercamientos al indio, que sin duda (tal viez Magdaleno supo ir algo más lejos) es paternalista y externo. Desde luego, tampoco se les puede exigir lo que no estaba a su alcance, y sus limitaciones no eran otras que las comunes a la literatura de denuncia que por entonces se practicó en Hispanoamérica. En el carácter de esa denuncia reside tal vez la especificidad mexicana, o al menos la especificidad de López y Fuentes: en otros países esa denuncia constituyó a menudo una manifestación de oposición a los regímenes políticos vigentes; en el México de Lázaro Cárdenas era eso quizá, pero a la vez también una consecuencia de la reactivación revolucionaria impulsada por un gobierno que trataba de avanzar por caminos abandonados, a la vez que descalificaba a sus predecesores en el ejercicio del poder.

Fruto de esa época, en El indio se incluyen la denuncia, la reflexión sobre el procedimiento para mejorar las condiciones de vida de los naturales, y tal vez el desencanto, todo ello en estrecha relación con los hechos de la Revolución. Al cabo, si la situación del indígena es como es, eso se debe al fracaso del proceso posrevolucionario. Los recursos narrativos de López y Fuentes son semejantes a los que muestran otros autores del momento: la novela es en realidad una sucesión de cuadros o escenas aisladas, enlazadas apenas entre sí, y con el protagonismo asignado a masas anónimas. Desde luego, los términos en que se plantea el problema del indio no son económicos, y menos aún marxistas, aunque de algún modo esté presente la cuestión de la posesión de la tierra. De las tres partes que constituyen la obra, la primera se dedica sobre todo a denunciar la actitud del blanco hacia el indio: comienza cuando a un poblado indígena aislado entre las montañas llegan tres exploradores en busca de oro (oro que supuestamente ocultan los naturales), y esa irrupción altera la armonía (una muchacha del lugar es acosada y tal vez violada, y un joven indio que guía a los viajeros es maltratado para que desvele un secreto que no posee); la venganza no se hace esperar (los intrusos dejan un cadáver en su huida), y luego llegan represalias que no se consuman, porque los indios, perfectos conocedores de la justicia de los blancos, abandonan el poblado refugiándose en las montañas. Olvidado el incidente (segunda parte), López y Fuentes ofrece una serie de cuadros sobre las costumbres del indígena, trabados por una leve anécdota amorosa que concluye trágicamente entre datos sobre la manera de vivir de los naturales. Y a la crítica de la Revolución se dedica la última parte: el conflicto llega hasta el indio apenas como el rumor de «algo muy grave que estaba sucediendo entre la gente de razón», y eso ya en fecha tardía, cuando «un cabecilla subió al caserío para quebrar la calma propia de las alturas en que los naturales ya se creían para siempre. Había sido que el jefe de la partida, no conociendo la región, se perdió en una violenta caminata. Además de exigir víveres, reclamó una docena de jóvenes que le sirvieran de guías; 
pero los dotó inmediatamente de carabinas e hizo que caminaran en vanguardia. Nunca regresaron» ${ }^{8}$.

Sobre el trato (la crueldad y el desdén) dispensado al indígena por quienes hablaban de su redención mientras se desarrollaban los acontecimientos bélicos, habían sido explícitas algunas anécdotas brutales incluidas en Campamento. En El indio López y Fuentes se limita a dejar constancia del abandono en que los naturales permanecen tras las luchas, solos frente a las epidemias que los diezman hasta que también inesperadamente aparece — «con su aire de funcionario prominente, con la pistola al cinto y montando un magnífico caballo, tenía el aspecto de un cabecilla» (97)— «el diputado», asegurando que la revolución se había hecho por ellos, para los indios. Estos se ven así comprometidos en tareas como la construcción de una carretera y de una escuela, que realizarán con su único esfuerzo y para beneficio ajeno, obligados por el poder político, a la vez que las presiones del clero los fuerzan a levantar una iglesia. López y Fuentes acierta a resumir la situación: «... dos días para la autoridad civil y dos días para la otra autoridad. Cuatro días sin descanso y sin salario a la semana...» (101). Desde luego, no ignora los esfuerzos que pretendieron incorporar al indígena a la vida nacional, pero sabe que hasta ese momento han fracasado, entre el desaliento y la escasez o carencia de recursos para llevar adelante los planes de educación previstos. La conclusión es pesimista, y queda en boca de uno de los ancianos del pueblo: «La escuela, cuando no se tiene lo necesario para vivir, es un lujo» (111). Nada ha cambiado sustancialmente: el indígena continúa pagando contribuciones personales abolidas y, ocupado en trabajos ajenos, es incapaz de sacar rendimiento a las tierras que tal vez se le ceden. Hay algunas soluciones poco gratas, y en la novela se apuntan: la renuncia a ese mundo en casos aislados, para ocupar la escala más baja en el mundo de los blancos y de los mestizos, o la ascensión por medio de la política, como ese personaje indígena criado entre blancos que sabe leer y escribir y por eso es ya un ser extraño a los suyos, entregado a la causa de los indios primero y al medro personal después. Su condena no parece tan absoluta como la de la actividad política en sí misma, personificada en el diputado y en ese «líder» campesino que es un indio alfabetizado: «La política - resume el autor - relegando a un segundo término la idea esencial de dotar de tierras a las mayorías como de lograr su mejoramiento económico. Largos cordones de trabajadores, indígenas y mestizos, recorriendo los caminos, llevados y traídos por los líderes, para hacer presentes sus fuerzas ante los políticos superiores» (122). En esas distracciones los sorprenderá el fantasma del hambre, olvidados de la siembra del maíz y del frijol, mientras, como siempre, «sólo saben que la gente de razón quiere atacarlos», y que «en la sierra y en el valle, los odios, en jaurías, se enseñan los dientes», y saben ahora también que el líder «goza de buena situación en la ciudad» (122).

Esta actitud negativa ante la Revolución era la que la Revolución hacía posible al realizar su propia crítica. Desde luego, no permitió a López y Fuentes ofre-

8 Véase El indio, prólogo de Antonio Magaña Esquivel, México, Editorial Porrúa, 5. edición, 1972, pág. 94. Las citas de la novela pertenecen siempre a esta edición, por lo que en adelante me limitaré a señalar tras ellas la página correspondiente. 
cer una visión positiva de los indígenas, miembros de una etnia postrada e incapaz de hacer su propia revolución, resignados a «las interminables tribulaciones de la raza» (27), y de continuo acosados por un «antiguo temor» para el que sobraban las justificaciones. De ellas hablan sus consecuencias, que han convertido en apenas recuerdo el esplendor del pasado: "por su estatura, conformación y aire de altivez», alguno de sus personajes - el joven que los blancos torturan en la primera parte - es para el autor «un digno vestigio de una raza que fue grande y fuerte» (15), y que aún (y eso es significativo) conserva su capacidad para sobrevivir en una naturaleza hostil, donde su adaptación al medio le hace superior al blanco. López y Fuentes, que alguna vez parece entusiasmado por la belleza física del indígena - «cobre repujado por el sol y el esfuerzo. Estatua en movimiento, hecha de cedro nuevo» (17) - , parece hacer suyas en alguna medida estas afirmaciones de un viaje tlachisqui: "Los patos nacen entre los tulares y, apenas han quebrado el cascarón, se echan al agua, sin que el padre o la madre les hayan enseñado a nadar. Las mariposas rompen su envoltura y vuelan libres por el cielo. La víbora nace y corre por entre la hierba, con la muerte en la boca... La tribu era así, también, y por eso ha podido sobrevivir a los sufrimientos. Nada tiene de raro que el niño sepa nadar sin haber aprendido. Lo que pasa es que en los últimos tiempos hemos desconfiado del instinto, influenciados por hombres de otra raza...» (45-46). Una visión positiva del instinto y de lo primitivo parece alentar en el narrador, y de ello no es difícil deducir el rechazo del racionalismo y de la civilización de los blancos. Esa actitud es fruto de la crisis ideológica que desde fines del XIX iba sustituyendo los planteamientos positivistas por otros de carácter vitalista, y que para los años treinta se había enriquecido de telurismo y de subconsciencia. Es significativo el epígrafe que Samuel Ramos puso en 1934 al famoso ensayo que tituló El perfil del hombre y la cultura en México: «Sólo partiendo del ALMA puede descubrirse la historia del hombre». Pertenecía a Oswald Spengler, el autor de La decadencia de Occidente.

Desde luego, esa visión de lo primitivo no salva a los indígenas imaginados por López y Fuentes. Tal vez la mala conciencia revolucionaria le impidió imaginar una salida — ante él queda un indio sin ambiciones, resignado e inmóvil, víctima en buena parte de «esas luchas que duran siglos de superstición, entre familias que se transmiten los odios, como una herencia» (69) - y sólo vio las consecuencias derivadas del fracaso de las reformas. De todos modos, si el clima posrevolucionario había determinado el escepticismo, también había obligado a abordar el problema. López y Fuentes - como hiciera Alcides Arguedas en Raza de bronce- lo planteó contrastando opiniones de distintos personajes en un tiempo que podemos suponer el del porfiriato. Entre los encargados de castigar a los indígenas al final de la primera parte de su relato, hay algunos (el presidente municipal y su secretario) partidarios del exterminio de esa raza inferior, tal como hicieran «los hombres progresistas y prácticos de otros países»: los indios — «insubordinados, holgazanes, borrachos, ladrones»-son «refractarios a todo progreso», «un verdadero lastre para el país». Se comentan - lo hace un profesor que puede ser el alter ego del autor- algunas soluciones posibles al problema indígena, como «colonizar con raza blanca los centros más compactos de indígenas, 
para lograr la cruza», naturalmente con ejemplares superiores que son los blancos, naturalmente para lograr mestizos, «el factor más importante y progresista»; también se hace referencia a la incorporación del indio por medio de la escuela, lo que provoca de inmediato las reticencias del alcalde: «¡Edúquese al indio y veremos después quién cultiva la tierra! De no exterminársele, es necesario dejarlo en el estado en que se halla, trabajando para los que física e intelectualmente somos superiores!». Todo esto se encuentra en las disputas de siempre, y desde luego son razonamientos frecuentes a finales del XIX. Tal vez la que cito a continuación era la teoría del autor, o al menos es la que corresponde al espíritu de la novela: «Mi teoría - explica el profesor - radica en eso precisamente, en reintegrarles la confianza. ¿Cómo? A fuerza de obras benéficas, pues, por fortuna, el indio es agradecido; tratándolos de distinta manera; atrayéndolos con una protección efectiva y no con la que sólo ha tenido por mira conservarlos para sacarles el sudor, como cuidamos al caballo que nos carga; y, para ello, nada como las vías de comunicación, pero no las que van de ciudad a ciudad, por el valle, sino las que enlacen las rancherías; las carreteras enseñan el idioma, mejor que la escuela; después el maestro, pero el maestro que conozca las costumbres y el sentir del indio, no el que venga a enseñar como si enseñara a los blancos. Con ello labrarán mejor la tierra, la que ya tienen, o la que se les dé» ${ }^{9}$.

No sé si eso justifica el brusco cambio de actitud del alcalde, su arrepentimiento, su identificación repentina con la raza perseguida, «nuestra raza», ésa que existe a pesar de las apariencias, a pesar de las diferencias tribales y del desconocimiento mutuo, y que sólo espera que se la redima. Tal vez López y Fuentes estimaba que la fuerza de los razonamientos era avasalladora hasta el punto de modificar en un instante las convicciones de cualquiera, o quizá mostraba con alguna ironía la facilidad con que podían cambiar de actitud quienes detentaban el poder. En cualquier caso, lo decisivo en esa novela es que por primera vez se denunciaba la situación del indígena — su miseria, los abusos que soportaba, la arbitrariedad de unas leyes sólo y siempre perjudiciales para él-, y eso tenía que ver de algún modo con la Revolución. Y otra novedad de interés: en El indio se realizaba, como nunca antes en una novela mexicana, la descripción de ritos, costumbres, fiestas, diversiones, supersticiones o creencias de los indígenas. Se hacía desde el exterior - con evidentes intromisiones de un autor que se ve en la necesidad de explicar un mundo desconocido-, pero se hacía, y de ese modo se daba un paso decisivo hacia la comprensión del mundo indígena.

Al parecer no se tardó mucho en constatar el fracaso de las campañas educativas o de reinserción, que suponían privar al indígena de su identidad. Tal vez se prefirió preservar su identidad y eso justificó que se olvidasen los planes de integración. El hecho es que el indio quedó pronto abandonado a sí mismo, al menos desde que el gobierno de Manuel Ávila Camacho (1940-1946) orientó la política mexicana hacia otras preocupaciones. Entonces los políticos e intelectuales prefirieron penetrar en su cosmovisión, con el fin justificado de conservar las peculiaridades de su raza dentro de un país ahora algo más respetuoso con la pluralidad cultural, o tal vez con intereses distintos. Los abundantes estudios realizados por

9 Véanse las págs. 30-34. 
etnológos, antropólogos e historiadores facilitaban el acceso a la mentalidad indígena, y los novelistas también se vieron afectados por los descubrimientos: de algún modo dejaron a un lado la protesta para penetrar respetuosamente en ese mundo extraño, tratando de precisar los caracteres de una identidad distinta. Es lo que ocurre en Nayar (1941), de Miguel Angel Menéndez, y sobre todo en Juan Pérez Jolote (1948), de Ricardo Pozas (verdadero estudio de antropología social realizado por un antropólogo) y en El callado dolor de los tzotziles (1949), de Ramón Rubín. Estas últimas obras elegían el punto de vista del indígena a la hora de narrar, y esa experiencia había de condicionar en adelante el desarrollo de la narrativa indigenista.

También en este sentido tuvo López y Fuentes algo que decir, y lo dijo ya en 1944, en Los peregrinos inmóviles. Su manera literaria no había variado apenas: continuaba siendo la propia de un narrador urgido por la necesidad de relatar acontecimientos, proclive a un estilo conciso y directo, acostumbrado o resignado a ofrecer una sucesión de escenas sin demasiada trabazón argumental, pero ahora su reflexión pretendía abarcar de algún modo la historia de México y el destino de los indígenas, estrechamente relacionados entre sí. Quería volver sobre una historia que había simplificado excesivamente en El indio - «el giro que tomó la fiesta (llegó a resumir allí) fue como la historia de cuatro siglos: primero las danzas, la música, el volador, en una palabra, la tradición; y luego , el alcohol» (57)—, y hubo de dar a Los peregrinos inmóviles una condición simbólica, pues no en vano eran tiempos en que nuevos narradores daban nuevas posibilidades a la literatura mexicana: Revueltas, Yáñez y Rulfo, entre otros, realizaron en esa década una labor renovadora con la que las aportaciones de López y Fuentes guardan evidente relación. Se trataba - aunque el éxito no fuese total- de adentrarse en el mundo del indígena, al que se le concede una voz propia para que sea él quien expresa los conflictos que padece, y que - esto también es una novedad- parecen sobre todo interiores, psicológicos, derivados de su enfrentamiento cultural con el blanco y también del mestizaje que en alguna medida se ha producido inevitablemente. Desde luego, López y Fuentes no deja de ser el que era: prodiga las descripciones costumbristas para las que se mostraba singularmente hábil, pero, consecuente con la evolución que he señalado, en Los peregrinos inmóviles trata de que esas descripciones sean las que puede ofrecer la cosmovisión indígena: se revisan las costumbres como parte constitutiva de unas tradiciones que sus personajes viven y sienten, lo que de inmediato dota a los indios de una complejidad psicológica inusitada. Eso era, en alguna medida, consecuencia de los planteamientos nacionalistas: los indios se habían convertido en un aspecto de los que conformaban la psicología nacional, o tal vez en un pretexto para hablar de una identidad escindida o mestiza difícil de asumir. Podríamos extraer de ello conclusiones tan negativas como las que esta novela mereció a algunos de los más notables estudiosos de la novela mexicana: "Lo que queda es un intento abortado de ver el mundo desde la perspectiva indígena, un simbolismo impropio y un montón de información exterior acerca de lo que es el indio» ${ }^{10}$.

10 Véase John S. Brushwood, México en su novela, México, Fondo de Cultural Económica, 1973, pág. 30-34. 
Esa crítica pierde consistencia si se piensa que toda obra no muestra otra cosa que la cosmovisión de su autor, y no es otro el caso de Los peregrinos inmóviles. Lo que queda y merece atención es precisamente ese esfuerzo para adoptar el punto de vista del indio, y a la vez para ofrecer una interpretación de ese mundo extraño que el título de la obra ya permite adivinar.

También esta novela consta de tres partes — «El corazón del mundo», «Maíz» y «La serpiente»-, la segunda de las cuales es un largo paréntesis en la narración de los hechos que ocurren en el tiempo presente: la constituyen los recuerdos del anciano Marcos, que rememora el pasado desde los tiempos de su niñez, cuando a consecuencia de una revolución imprecisa (tal vez la de Benito Juárez) que hablaba de igualdad, fraternidad y justicia, y que protagonizaban hombres partidarios de la causa de los pobres, su tribu inició una larga marcha que fue a la vez una huida y una búsqueda que se prolongan hasta ese presente que es el de la novela. En esa peregrinación se conjugan las alegrías y los temores de la libertad, y la tribu se fragmenta una y otra vez en un caminar que multiplica los episodios pero que parece mostrar un episodio único y reiterado de soledad y de desamparo: el indio aparece siempre maltratado, acosado por los hombres y por la naturaleza -o por los dioses ajenos, más poderosos que los suyos-, avanzando sin rumbo y sin horizonte, a merced de la serpiente del odio que anida en el corazón de los humanos, hasta llegar a esa ciudad en la que habitan en el presente y que para ellos constituye el corazón del mundo. La independencia de ese relato es total, y sin embargo en él se encuentran las claves del presente, y también del futuro. Lo que del presente se cuenta no es fácil de precisar: funcionarios encargados del censo llegan a una población de la meseta, y las respuestas que reciben permiten contrastar las visiones dispares que los pobladores tienen de su propio mundo, un microcosmos cerrado que para ellos es el centro del universo, y tal vez el universo. En ese ámbito se desarrolla una débil peripecia argumental que se inicia con el llanto interminable de un niño, que su madre considera aquejado de tlazol o maleficio del amor. Sólo la muchacha que tal vez lo ha causado podría curarlo saltando sobre el niño, lo que equivaldría a reconocer su culpabilidad. La historia incluye sabios consejos de los ancianos, la curación del niño, la boda de la muchacha culpable con un joven del poblado rival y los riesgos que derivan de ello, con el despertar de odios y rivalidades que el ambiguo final de la novela parece revelar incesantes: tal vez la raza está destinada a continuar esa peregrinación que no lleva a ninguna parte, que es apenas una manifestación de la inmovilidad.

De todos modos, algo ha cambiado en algún momento de la peregrinación: «Vimos con asombro - recuerda el narrador - que ya no éramos los mismos: hablábamos otra lengua y entre nosotros había caras que parecían miniaturas de los amos... Jamás habíamos caído en la cuenta (hasta entonces) de que ya éramos otros... Al ver cómo se juntaban dos ríos, uno de agua clara y otro de agua oscura, pensé que eso éramos nosotros: agua de dos ríos» ${ }^{11}$. Eso explica que en el

11 Véase Los peregrinos inmóviles, México, Ediciones Botas, 1944, pág. 180. Las citas pertenecen siempre a esa edición, por lo que en adelante también en este caso me limitaré a señalar tras ellas la página correspondiente. 
presente no falten entre los pobladores los que se consideran muestra de una personalidad escindida y difícil de asumir. En torno de burla, López y Fuentes juega por boca de Antonio, uno de sus personajes, con un símbolo fundamental de ese mestizaje: Malintzin, la Marina que sirvió de intérprete y amante a Hernán Cortés; «la verdadera causa de que vean ustedes tanta gente casi blanca — explicase debe a un fenómeno que yo llamo malinchismo... Se trata de esa fascinación que experimentó la Malinche y que desde entonces ha dado motivo a que muchos extranjeros no vengan con otra mira que buscar una mujer del país, con una fortuna: verdadero negocio que hemos bautizado con la referencia a una parte del pantalón...» (17). Ese origen marcado por el interés o la violencia se revela traumático, difícil de asumir, y sin embargo sobre el color de la piel se articulan diferencias económicas que distorsionan el papel de la raza en la estratificación de esa sociedad — «los ricos o con destacada posición social, acaban por decir y creer que son blancos» (17)—, hasta el punto de que se prefiere al cabo la condición mestiza, porque ella revela una marginación menor, una esperanza de escapar de la miseria absoluta. Eso no es sino otra manifestación de esa carencia de identidad que es la identidad del indio y del México contemporáneo, la que el viejo indio Marcos observa y alienta para la conquista de un futuro: «Ustedes —asegura a las gentes del pueblo- yo no son indios: ustedes son gente blanca, gente casi blanca (...) ustedes son gente civilizada, muchachos: son políticos, funcionarios, con muchas lecturas... Ustedes ya no son indios... Lo conveniente es que se miren como iguales... Morenos o blancos, todos iguales... No hay razas puras...» (48).

La dureza de las condiciones de vida no se ha modificado, y López y Fuentes vuelve a ponerlo de manifiesto. En ese sentido, la novela pretende constituir aún una denuncia, pero lo cierto es que eso ya no es la preocupación fundamental. La confusión de sus propias ideas generó un texto que es una reflexión confusa y sugerente sobre las consecuencias de la historia: las consecuencias del progreso, de la «cultura» de origen europeo, de la lengua y la sangre de los conquistadores. La historia es la responsable del mestizaje y de la desaparición de la cosmovisión mágica o mítica primitiva, que apenas sobrevive como otra de las manifestaciones, tal vez la más compleja, de ese mestizaje. Los peregrinos inmóviles ofrece una rica visión de ese mundo extraño que es el de los indios contemporáneos de México, a sabiendas tal vez de que no hay otro México que ése, por lejano y difícil de asumir que resulte para los europeos y europeizados. De paso, ofreció un relato de alguna manera cíclico, configuró un universo ambiguo y contradictorio, e hizo saber que la raza era como «esas plantas que sobreviven a pesar de todas las mutilaciones» (154). Ahí radicaba tal vez el mensaje esperanzado de esa novela, eslabón importante en la trayectoria hacia un nuevo indigenismo. 
